\title{
Content Analysis of a Predominately African-American Near-Death Experience Collection: Evaluating the Ritual Healing Theory
}

\author{
James McClenon, Ph.D. \\ Elizabeth City State University, Elizabeth City, NC
}

\begin{abstract}
Twenty-eight near-death experience (NDE) narratives were selected from 1,832 anomalous experience accounts collected from predominately African-American respondents in northeastern North Carolina. Analysis of this sample allowed testing hypotheses regarding NDEs and the ritual healing theory. The North Carolina sample revealed a lower incidence of NDE core features than Bruce Greyson found in a sample of International Association for Near-Death Studies (IANDS) members, but equivalent to that found by Mark Fox in a British sample and by Kenneth Ring in an American sample. As Fox reported, comparison of crisis to non-crisis accounts revealed no significant differences in frequency of NDE features. Although no narrative features in the sample stories indicated ethnicity, content analysis revealed different frequencies of NDE type and greater incidence of negative emotion than previous researchers found. Accounts portrayed elements associated with shamanism and shed light on the process by which NDEs shape folk religious belief. All in all, hypotheses derived from the ritual healing theory were supported.
\end{abstract}

KEY WORDS: near-death experiences; African-Americans; shamanism; ritual healing theory; folklore.

Near-death experiences (NDEs) are defined as "profound psychological events with transcendental and mystical elements, typically occurring to individuals close to death or in situations of intense physical or emotional danger" (Greyson, 2000, p. 315). NDEs are thought to have recurring "core elements," such as ineffability, out-ofbody experience, and encounter with light, occurring crossculturally.

James McClenon, Ph.D., is Professor of Sociology in the Department of Social Sciences at Elizabeth City State University. Reprint requests should be addressed to Dr. McClenon at the Department of Social Sciences, Elizabeth City State University, Elizabeth City, NC 27909; e-mail: jmmcclenon@mail.ecsu.edu. 
Although Mark Fox (2003) argued that many NDE-type episodes are unrelated to death, this study will refer to experiences having the features identified by Raymond Moody (1975), Kenneth Ring (1980), and Bruce Greyson (1983) as NDEs or "NDE-like" accounts.

Comparison of accounts from American, European, Middle Eastern, African, Indian, Asian, Pacific, and Native American peoples allow insights into the nature of NDE core features (Becker, 1981, 1984; Kellehear, 1996, 2001; McClenon, 1991, 1994; Murphy, 2001; Wade, 2003; Zaleski, 1987). Although researchers have not achieved complete consensus regarding these core features, they generally concur that such elements exist, that accounts are shaped in part by expectation and cultural processes, and that these experiences have transformational capacities (Fox, 2003; Greyson, 2000; Kellehear, 1996; Moody, 1975; Moody and Perry, 1988; Morse and Perry, 1992; Ring, 1980, 1984; Sutherland, 1992; Zaleski, 1987).

The present study follows Fox's (2003) strategy of analyzing a sample of NDE-like accounts taken from a larger collection of experiential narratives. Fox (2003) analyzed 91 NDE-like accounts selected from the collection of 6,000 religious experiences at the Alister Hardy Society Religious Experience Research Center (RERC) at the University of Wales, Lampeter, Great Britain. Using parallel methodology, the present study analyzed 28 NDE-like accounts selected from 1,832 anomalous experience narratives, collected from a predominately African-American population in northeastern North Carolina. The populations generating these two samples differ markedly in culture and ethnicity. Because previous major American studies contained only a small percentage of African-American respondents (Greyson, 1983; Ring, 1980), comparison of findings allows insights regarding the impact of ethnicity on NDEs.

\section{Theories Regarding NDEs}

Meanings attributed to recurring features are the basis of theories explaining NDEs. Some argue that core features reflect life after death: the NDEr is thought to have glimpsed the "other side" and returned to tell the tale. Others attribute NDEs to the physiology of dying. Susan Blackmore (1993), for example, argued that temporal lobe activities create the "life review," endorphins generate feelings of peace, and alterations in levels of oxygen and carbon dioxide create visionary perceptions. Opponents of this theory provide counterarguments, 
refuting each explanation. They point out, for example, that perceptions associated with oxygen deprivation differ from the clear visions NDErs report: "Every theory that has been advanced to explain the NDE is rapidly confronted by a range of critiques and counterclaims" (Fox, 2003, p. 153).

An alternate paradigm portrays NDEs as one of various anomalous experiences reflecting the genetic basis for human religiosity. NDEs are viewed as a form of religious vision, originating with shamanism, humankind's first religious form. This orientation does not necessarily deny NDEs' religious authenticity, since shamanism may involve paranormal and spiritual forces.

Studies within this paradigm vary with regard to focus and orientation. Crosscultural comparisons of accounts allow insights into the degree to which physiology shapes experiential forms, while sociopsychological studies portray how anomalous perceptions create, and are also shaped by, folk belief (McClenon, 1994, 2002a). Carol Zaleski, for example, compared medieval European NDEs to modern accounts and concluded that

the otherworld journey is a work of the narrative imagination. As such it is shaped not only by the universal laws of symbolic experience, but also by the local and transitory statutes of a given culture. (Zaleski, 1987, p. 7)

Such "universal laws" seem derived from shamanism's physiological basis, demonstrated through crosscultural comparison of trance (Winkelman, 2000). Fox (2003) observed that NDEs are parallel in many respects to shamanic journeys, and that NDE "transformations" are similar to shamanic initiations. Timothy Green (1996, 1998, 2001), Ring (1989, 1990), and William Serdahely (1991) discussed numerous example cases supporting this argument.

The ritual healing theory provides an evolutionary scenario describing how genes associated with shamanism, religiosity, and anomalous experience were selected. During the many millennia that Homo sapiens practiced shamanism, the genes of those more receptive to ritual healing became more prevalent. These genes are linked to religiosity, dissociation, and anomalous experiences supporting shamanism. NDEs can be viewed as one of many forms of anomalous experience providing the basis for shamanism. Other experiences include apparitions, paranormal dreams, waking extrasensory perceptions, out-of-body experiences (OBEs), and psychokinesis (McClenon, 1994, 2002a). As do NDEs, shamanism and the anomalous experiences supporting it reveal recurring "core features." Shamanism 
involves practitioners going into trance and communicating with spiritual forces for the benefit of others (Eliade, 1974). Although shamanic practices changed as human societies acquired increasingly complex social forms (Winkelman, 2000), genotypes allowing dissociation and trance are hypothesized to generate universal elements within anomalous and religious experience (McClenon, 2002a).

Much evidence supports the argument that NDEs and shamanic visions are neurologically similar. Kellehear's (1996) crosscultural analysis of NDEs led to a more accurate understanding of their core features, revealing that some elements are found only in technologically complex societies. Kellehear's (1996) list of core features, including darkness, encounters with "other beings," and arrival at an "other world," are equivalent to the core shamanic elements described by Mircea Eliade (1974), including trance, soul travel to a spirit world, and contact with spiritual beings. Ethnographic accounts reveal parallel features in shamanism and NDEs (Green, 1996, 1998, 2001; Ring, 1989, 1990; Wade, 2003). For example, the Oglala Sioux shaman Black Elk reported an NDE when he was 9 years old, an event regarded as his shamanic initiation (Neihardt, 1988/1932). Black Elk, and those around him, regarded NDEs as equivalent to shamanic visions, since these experiential forms corroborated each other regarding the nature of spiritual worlds. In parallel fashion, medieval Chinese and Japanese monks perceived their NDEs as equivalent to meditative visions, since their experiential content coincided (McClenon, 1991, 1994).

Correlational studies support the argument that NDEs are a form of shamanic vision. Psychological correlates of NDEs are similar to those of shamanism and associated anomalous experiences. Variables correlated with the incidence of NDEs, extrasensory perception, and capacity for shamanic vision include hypnotic ability, memory of dreams, use of mental imagery, absorption, and fantasy proneness (Greyson, 2000; Irwin, 1985; McClenon, 1997, 2002a). NDErs are more likely to report childhood trauma and paranormal perceptions than are nonNDErs (Ring, 1984, 1992); the biographies of shamans, spiritual healers, and psychic practitioners reveal a similar pattern (Emmons and Emmons, 2003; McClenon, 1994, 2002a).

Shamanism involves complex processes in which certain people, having dissociative tendencies often linked to psychosomatic disorder, experience anomalous and extrasensory perceptions, gain reputations for supernatural ability, and undergo initiations that typically involve symbolic "deaths" and "rebirths" (Eliade, 1974). The process is associated with creativity and, as a result, shamanism is regarded as 
"a good outlet for the self-expression of those who might be described as being endowed with an 'artistic temperament"' (Haviland, 1997, p. 651). Shamanic visions often have innovative qualities, designed to help people adjust to changing situations. Visions often reflect hypnotic "creative problem-solving" (Lynn and Sivec, 1992), since they may provide solutions to problems that would not have been devised or accepted if they had originated through other means. As a result, shamans perform rituals that create hypnotic and placebo effects with proven therapeutic benefits.

NDEs reveal parallel features. They have utopian qualities, providing images of an afterlife contributing to transformation (Kellehear, 1996). They provide "solutions" to the problem of death, valuable to both individuals and their communities. Throughout history, NDEs have creatively shaped religious beliefs in a manner contributing to psychological health, sometimes providing images preceding formal changes in theology (McClenon, 1991, 1994). Although the shamanic approach to NDEs emphasizes imagination, this orientation need not be regarded as completely materialistic, since some shamanic visions provide special insights into reality (Ring, 1990).

This is not to say that all NDEs are exactly like shamanic visions. Anomalous experiential forms are shaped by physiology, culture, expectation, and creativity, with the later three factors contributing to variance among cultures. NDEs occur in special settings, surrounded by expectations that differ from those associated with shamanism; variations in setting generate variations in experiential content.

The ritual healing theory argues that shamanism and NDEs are linked by their common physiological basis. Hominid genotypes allowing dissociative and hypnotic capacities protected against the psychological effects of trauma (McClenon, 2002b). Such genotypes contributed to the ability to perceive apparitions, paranormal dreams, waking extrasensory perceptions, psychokinesis, OBEs, and NDEs. Many researchers have found significant correlations between the propensity for dissociation or hypnosis and the incidence of paranormal experiences (Kumar and Pekala, 2000), including NDEs (Ring, 1992). Among Homo sapiens, these anomalous experiences generate beliefs in spirits, souls, life after death, and magical abilities, concepts providing the basis for shamanism. The ritual healing theory argues that shamanic rituals, based on placebo and hypnotic effects, provided greater survival benefits to those with dissociative or hypnotic genotypes, causing an evolutionary cycle that led to the modern genetic basis for religiosity. This theory coincides with a growing body of 
evidence, derived from twin studies, indicating that religious attitude, interests, and practice have a genetic basis (D'Onofrio, Eaves, Murrelle, Maes, and Spilka, 1999; Waller, Kojetin, Bouchard, Lykken, and Tellegen, 1990).

\section{Hypotheses}

The ritual healing theory allows hypotheses pertaining to NDEs. I tested these hypotheses through analysis of a sample of narratives gathered from a predominately African-American population in North Carolina and through comparison of these results to others' findings.

\section{Hypthesis 1: The Biological Basis of NDEs}

Any large collection of NDE narratives should reveal core features reflecting the biological basis of this experiential form. The incidence of features can be measured using scales based on the work of Moody (1975), Ring (1980), and Greyson (1983).

\section{Hypothesis 2: The Source of NDEs: Crisis versus} Non-crisis Accounts

Fox (2003) identified 32 "crisis" cases and 59 "non-crisis" cases (not related to danger or death) in his sample of 91 "NDE-like" accounts. He determined that "the average number of Moody's original 15 NDE elements in the crisis and non-crisis accounts examined were 3.3 and 2.9 respectively, a difference of only 0.4 " (Fox, 2003, p. 325). These results reduce faith in the "dying brain" theory, since equivalent perceptions were found in dying and non-dying contexts. The ritual healing theory argues that core features in crisis and non-crisis accounts should be equivalent in the North Carolina sample, since NDEs are hypothesized to be related to propensity for experiencing visions rather than to dying.

\section{Hypothesis 3: The Cultural Shaping of NDEs}

The ritual healing theory suggests that both visions and NDEs are shaped by expectation, culture, and creativity. As a result, any large collection of NDEs should reveal features reflecting these factors. Analyses conducted by Fox (2003), Ring (1980, 1985), and Greyson (1983, 1985) provided data for comparison with the North Carolina 
sample. I compared samples with regard to frequency of core elements, incidence of negative emotion, and NDE type. Because this is an exploratory hypothesis, I did not predict directions of differences.

\section{Hypothesis 4: The Shamanic Nature of NDEs: Individual Transformation}

The ritual healing theory predicts that people who report NDEs are more likely to perceive other forms of anomalous experience. It also hypothesizes that NDEs and other anomalous experiences generate beliefs in spirits, souls, life after death, and magical abilities. Such beliefs motivate frequent experiencers to seek shamanic skills and play shamanic roles, performing magical services for others. This hypothesis can be investigated through qualitative case analysis: we would expect to find accounts of people who report many anomalous experiences to take on spiritual healing roles.

Hypothesis 5: The Social Impact of NDEs:

Social Transformation

The ritual healing theory argues that audiences hearing NDE stories tend to increase their belief in life after death. Qualitative analysis of stories deemed most interesting by listeners, and the impacts attributed to these stories, should shed light on the process by which folk religion is created through oral transmission of personal experience.

\section{Methodology}

Between 1988 and 2003, I required students in my Introduction to Anthropology class at Elizabeth City State University in Elizabeth City, NC, to ask a minimum of three individuals the question: "If you have had a very unusual experience, would you describe it?" Students transcribed respondents' accounts and provided their opinions of each story.

The collected narratives reflect the average student at Elizabeth City State University (ECSU). ECSU is a small, predominately AfricanAmerican college, with about 2,000 students during the time of the study. Elizabeth City, with a population of about 17,000 (half of whom are African-American), is located in rural northeastern North Carolina, an area regarded as economically disadvantaged. Narratives 
that included demographic data indicate that 71.2 percent of the informants were African-American and 68.5 percent were women. Among these informants, 15.2 percent were white-collar workers, 29.3 percent blue-collar workers, 37.4 percent full-time students, 7.5 percent housewives, and 8.9 percent retired.

Through analysis of accounts previously gathered in the United States, China, and Japan, I had previously identified naturally occurring categories of anomalous experience, such as apparitions, paranormal dreams, waking extrasensory perception, psychokinesis, sleep paralysis, and out-of-body experiences. I devised coding guidelines, based on core elements within each category, and classified narratives regarding their experiential form. Between 1978 and 1997, my students collected 1,215 anomalous experience accounts; I have published reports based on these data previously (McClenon, 2000, 2002a, 2002b). Between 1997 and 2003, 617 more accounts were collected and sorted into the previously devised categories.

The original coding system provided no category for "near-death experience." Narratives of the NDE form were either classified as "outof-body experiences" or placed in a "miscellaneous" category that included religious visions. Careful reading of Fox's (2003) classification strategy allowed identification of NDE-type accounts. Fox (2003) described "crisis" experiences, in which the account involved the possibility of death, and "non-crisis" experiences, in which that possibility was not present. He noted that non-crisis experiences involved no "life-threatening crisis" but revealed "a range of traditional NDE elements, including out-of-body experiences, tunnels, light and so on" (Fox, 2003, p. 247).

Using Fox's strategy, I identified 28 accounts as "NDE-like" experiences. Among these 28 respondents, 20 were African-American and 8 were Caucasian; 10 were male and 18 female; and their average age was 39 years. I instructed nine ECSU undergraduate students in Fox's (2003) system of classifying crisis, non-crisis, and deathbed experiences: stories involving hospital visits were classified as "crisis" accounts; stories lacking a life-threatening event were coded as "noncrisis"; and episodes in which the person having the vision died and did not come back to life were labeled "death-bed visions." This strategy allowed identification of 22 crisis cases, 5 non-crisis cases, and 1 deathbed vision, which was excluded from comparative analysis.

Cases were evaluated, based on previous studies, regarding incidence of NDE core features (Moody, 1975; Greyson, 1983; Ring, 1980). Moody's (1975) 15-item list includes: (1) ineffability, (2) hearing the 
news of one's death, (3) feelings of peace and quiet, (4) hearing a particular noise, (5) traversing a dark tunnel, (6) feeling out of the body, (7) meeting others such as deceased relatives, friends, or religious guides, (8) meeting or experiencing a being of light, (9) perceiving a life review, (10) perceiving a border between life and death, (11) coming back to the body, (12) telling others of the experience, (13) perceiving effects on attitudes toward life, (14) gaining new views of death, and (15) corroboration of information gained from the otherworldly travels.

Ring's (1980) five "sequential stages" or "elements" include (1) feeling peace, (2) body separation, (3) entering the darkness, (4) seeing the light, and (5) entering the light. Moody and Ring scale scores were determined by counting the incidence of core elements. Greyson's (1983) 16-item NDE Scale quantifies NDE depth through questionnaire response. The scale, validated through Rasch scaling (Lange, Greyson, and Houran, 2004), allows classification of NDEs based on response to four subscales: cognitive, affective, paranormal, and transcendental. I slightly modified the wording of the NDE scale to make items applicable to a narrative text rather than a questionnaire to which narrators were asked to respond.

Following Fox's (2003) strategy, I directed coders to accept any mention of darkness as indicating Moody's (1975) tunnel element. Final coding was determined by averaging coders' scoring for each case.

\section{Results}

\section{Hypothesis 1: The Biological Basis of NDEs}

The finding of NDE core features in the North Carolina sample, as measured by all three scales, supports Hypothesis 1, as shown in Table 1.

Due to ambiguity in texts, lack of precise definitions in scaling systems, and variations in student coding skills, coders often failed to achieve consensus. The first example narrative, presented under "hypothesis 3 ," portrays ambiguity derived from imprecise definitions of "out-of-body experience." As shown in Table 2, equivalent coefficients of variation indicate that reliability was approximately equal among the scales. Average Pearson product-moment correlations 


\section{Table 1 \\ Mean Rates of Core NDE Features in North Carolina Sample and in Previously Published Studies}

\begin{tabular}{lll}
\hline \multicolumn{1}{c}{ Measure } & \multicolumn{1}{c}{$\begin{array}{c}\text { North Carolina } \\
\text { Sample }\end{array}$} & \multicolumn{1}{c}{$\begin{array}{c}\text { Previously Published } \\
\text { Study }\end{array}$} \\
\hline Fox's scale derived & 2.81 (crisis cases) & 3.3 (crisis cases) \\
$\quad$ from Moody (1975) & 2.87 (non-crisis cases) & $\begin{array}{l}2.9 \text { (non-crisis cases) } \\
\text { Ring (1980) scale* }\end{array}$ \\
$\begin{array}{l}\text { NDE scale } \\
\quad \text { Greyson, 1983) }\end{array}$ & 3.16 & 1.46 \\
\hline
\end{tabular}

* Summed proportions of "core experiencers" reporting each NDE "stage."

among coders for each scale, an alternate measure of reliability, varied from an acceptable minimum value of .70 to .87 .

Hypothesis 2: The Source of NDEs:

Crisis vs. Non-crisis Accounts

Table 3 compares average Moody, Ring, and Greyson scale scores of crisis and non-crisis accounts. As hypothesized, crisis and non-crisis average scores did not differ significantly. The non-crisis experience averages on the Moody and Greyson scales were actually slightly higher than the crisis experience averages.

Table 2

Reliability of Measures of Core NDE Features in North Carolina Sample

\begin{tabular}{lccc}
\hline \multicolumn{1}{c}{ Measure } & $\begin{array}{c}\text { Score }(N=27) \\
(\text { Mean } \pm S D)\end{array}$ & $\begin{array}{c}\text { Coefficient } \\
\text { of Variation } \\
(S D / \text { Mean })\end{array}$ & $\begin{array}{c}\text { Mean Correlation } \\
(R) \text { Among Coders } \\
(N=36)\end{array}$ \\
\hline $\begin{array}{l}\text { Fox's scale derived } \\
\text { from Moody (1975) }\end{array}$ & $2.83 \pm 0.73$ & 0.26 & .85 \\
Ring (1980) scale* & $1.16 \pm 0.33$ & 0.29 & .70 \\
NDE scale & $3.78 \pm 0.31$ & 0.31 & .87 \\
$\quad$ (Greyson, 1983) & & & \\
\hline
\end{tabular}

* Summed proportions of "core experiencers" reporting each NDE “stage." 


\section{Table 3}

Mean Rates of Core NDE Features in Crisis and Non-crisis Cases

\begin{tabular}{lcrrr}
\hline \multicolumn{1}{c}{ Measure } & $\begin{array}{c}\text { Crisis Cases } \\
(N=22)\end{array}$ & $\begin{array}{c}\text { Non-crisis } \\
\text { Cases }(N=5)\end{array}$ & $\begin{array}{c}t \\
(d f=25)\end{array}$ & $p$ \\
\hline Fox's scale derived from & & & & \\
$\quad$ Moody (1975) & 2.81 & 2.87 & -0.06 & .95 \\
Ring (1980) scale* & 1.18 & 1.07 & 0.48 & .64 \\
NDE scale (Greyson, 1983) & 3.69 & 4.13 & -0.32 & .76 \\
\hline
\end{tabular}

* Summed proportions of "core experiencers" reporting each NDE "stage."

\section{Hypothesis 3: The Cultural Shaping of NDEs}

Table 1 compares average incidence of NDE core features, as measured by the Moody, Ring, and Greyson scales. Average incidence of features in the North Carolina sample, as measured by the Moody scale, was equivalent to that found by Fox (2003) in his crisis and noncrisis samples. Average incidence of features in the North Carolina sample, as measured by the Ring scale, was only slightly lower than that found by Ring (1980). Average incidence of features in the North Carolina sample, as measured by the NDE scale, was much less than found by Greyson (1983).

The proportion of NDEs compared to other experiences was equivalent, perhaps coincidentally, to that found by Fox (2003). Fox found 91 "NDE-like" accounts within a 6,000-case collection, for an incidence of 1.5 percent. Among the 1,832 North Carolina cases, 28 "NDE-like" accounts were identified, for an incidence of 1.5 percent. Fox (2003) reported a far greater percentage of non-crisis accounts within his analysis sample (65 percent) than I found in the North Carolina sample (19 percent).

Typical accounts in the North Carolina collection were similar to typical NDEs published in the literature. There were no apparent differences between African-American and white respondents' accounts. The most common motif involved an anesthetized surgical patient viewing his or her body on the operating table from above while medical personnel dealt with a medical emergency. The modal value of core elements was one, most commonly an OBE. The more complex stories included many core features, typically OBEs, feelings of peace, seeing deceased relatives or Jesus, and perceiving a bright light. 
Content analysis reveals quantitative differences between the North Carolina accounts and other NDE collections. Ring (1980) listed percentages of people reporting his sequential NDE stages as 60 percent feeling peace, 37 percent separating from the body, 23 percent entering the darkness, 16 percent seeing the light, and 10 percent entering the light. The North Carolina sample differed markedly from that pattern, with 26 percent feeling peace, 63 percent separating from the body, 11 percent entering the darkness, 26 percent seeing the light, and none entering the light.

The North Carolina collection also lacked NDE forms reported by Greyson (1985, 1990). Greyson's (1983, 1985) NDE scale has four subscales: cognitive, affective, paranormal, and transcendental. He reported that his IANDS sample could be grouped into three major types: 43 percent described transcendental NDEs, 42 percent described affective NDEs, 16 percent described cognitive NDEs and none described paranormal NDEs. Because, in general, North Carolina NDE scale scores were low, only three individuals scored high enough in a subcategory to allow subscale classification using Greyson's system. In all three cases, these NDEs were "transcendental," involving traveling to another world and meeting deceased relatives or Jesus.

The 28 North Carolina NDE accounts included 99 positive responses to items in Greyson's NDE Scale. Of those positive responses, 42 percent were transcendental, 20 percent were affective, none were cognitive, and 38 percent were paranormal. By contrast, it can be calculated from Greyson's (1983) data that among his IANDS sample, 26 percent of the positive responses were transcendental, 37 percent were affective, 16 percent were cognitive, and 22 percent were paranormal. Seventy-five percent of Greyson's IANDS respondents stated that their experience included the feature of time distortion: "everything seemed to be happening all at once; or time stopped, or lost all meaning" (Greyson, 1990 , p. 156). Although the nine North Carolina students did not code a single respondent as reporting this feature, one narrative described possible "time distortion." If this case were coded as "positive," this would mean that only 4 percent of accounts included this element.

The North Carolina sample revealed higher percentages of negative emotions than did Fox's British or Ring's American samples. Among crisis cases mentioning emotions, Fox (2003) noted that 6 percent reported "negative or unpleasant" sensations and 12.5 percent reported mixed sensations. Ring (1980) noted that only 5 percent of reported feelings or emotions were negative. Among the 10 North Carolina "crisis experience" respondents mentioning emotions, 7 (70 percent) 
were positive and 3 (30 percent) were negative. Although North Carolina respondents mentioned 7 visits to heavenly realms and only one visit to hell, no heavenly visitor mentioned an emotion.

Comparison of non-crisis accounts also revealed a higher incidence of negative emotion within the North Carolina sample. Among Fox's (2003) non-crisis cases mentioning emotion, 5 percent portrayed negative feelings while 8.5 percent reported mixed experiences. Among 5 non-crisis North Carolina reports of emotions, two (40 percent) were negative, two (40 percent) were mixed, and one (20 percent) was positive.

\section{Discussion}

\section{Hypotheses 1-3: The Biological Basis, Source, and Cultural Shaping of NDEs}

The finding that the North Carolina collection contains NDE core features, as defined by the three scales (Hypothesis 1), supports the argument that NDEs have a physiological basis, since accounts from all over the world reveal similar core features. The finding that crisis and non-crisis accounts contain equivalent frequencies of core features (Hypothesis 2) replicates Fox's (2003) finding and supports the ritual healing theory: NDEs seem more closely linked to shamanic, visionary processes than to the physiology of dying.

Although we cannot be certain that variations among samples with regard to incidence of core elements and expression of negative emotions are a reflection of cultural differences, these variations seem to support Hypotheses 3. Differences in sample selection, story collection, and evaluation methodology may contribute to these variations. The North Carolina collection methodology, based on student interviews, differed from those used by other researchers. Ring's sample was gathered in Connecticut and Maine, and Greyson's sample was derived from members of IANDS throughout the United States. The Fox and North Carolina samples were not originally gathered with the intention of collecting NDE cases, as were the Ring and Greyson samples.

Greyson's IANDS members may have reported a higher incidence of core features because their experiences were sufficiently compelling to motivate them to join an organization dedicated to NDE research. In addition, Greyson's respondents were specifically asked about each item on the scale, whereas those providing North Carolina accounts 
were not. These methodological differences would contribute to a lower incidence of reported core elements within the North Carolina sample.

Qualitative analysis of the North Carolina accounts provides insights into these quantitative differences. Example cases demonstrate the similarity between crisis and non-crisis accounts. Three non-crisis respondents reported fear while out of their bodies, because they thought they might be dead. Two respondents described sleep paralysis, episodes where they awoke to find they could not move. An example case includes sleep paralysis, panic, and a form of OBE:

I awoke in a deep sweat. My eyes were open but I could not move. I looked above at the ceiling and I saw myself, my spirit, before my very own eyes. I remember praying, asking the Lord what was happening. I felt my heartbeat dropping and I began to panic. (Narrative 13)

As with many accounts, coders did not reach consensus on this narrative. A majority labeled this episode an $\mathrm{OBE}$ because the speaker's spirit left her body.

A second non-crisis night paralysis report mentioned both positive and negative emotions:

I decided to lie on my back in my bed to take a short break and rest.... I began to hear a faint whirring sound, similar to that of a vacuum cleaner.... I realized that ... something very strange was happening to me. My body began to shake ... in proportion to the intensity of the progressively louder whirring noise until it reached a point of violently shaking as if someone was shaking me with me having no control over it. At this point I felt as if I could be shaken no harder and the whirring sound could be no louder.

I experienced a floating sensation and could feel my inner self slowly rising upward towards the corner of the room, where the walls and ceiling meet. About a third of the way up, I could see my roommate continuing to sleep on the other side of the room in his bed. As I was baffled by this strange phenomena, I concluded that I must be dying and as I looked up at the corner of the room, I saw it open up to a long concrete stairway, similar to the ones used in the dorm to go from one floor to the other. At the top of this opening was the brightest white light you could imagine.

As I stared at this light, the most peaceful, alluring feeling came over me and I was convinced that I was dying and was so happy and unafraid, and accepting. I felt that I was in the process of going to heaven to see Jesus. The instant I graciously accepted this fact, the whole floating upward process speeded up dramatically and I said to myself, "This is really happening." Now, I started to panic and I tried to call out to my roommate but nothing would come out of my mouth. At this instant, the whole process immediately stopped and I was again in my body, lying flat on my back in my bed. I was white as 
a sheet, and was in a cold, clammy, light sweat, almost scared to even breathe. (Narrative 22)

This story illustrates how non-crisis accounts can be equivalent to crisis NDEs.

One non-crisis respondent even described a visit to hell and then heaven, the only "hell visit" in the collection:

I had worked real hard that day and fell asleep on the sofa. Then I thought I got right back up and I started walking around and I noticed someone lying on my sofa. I thought about calling 911 but the person seemed to be harmless. I walked over and it was me. I started panicking because I thought I was dead. Then I screamed and it felt like something was pulling me very fast throughout the house. When I blinked my eyes and then opened then back up I was in hell. I saw many people there that I knew and they were burning, screaming, and asking me for help. I was yelling for a while too until I realized that I was not burning.

As soon as I realized I was not burning, I felt another pull and this time when I opened my eyes I believe I was in heaven. I was in the middle of a forest but it was no ordinary forest. I saw no grass on the ground or dirt. The ground looked golden. Then I felt another pull and this time I ended up in what looked like a foggy tunnel. I heard an echo saying my name, "Shondra, you have a choice. You can either follow your Lord and Savior Jesus Christ or death come unto you." Then I went back to my body and then I was awake. Once I got myself together I realized that the Lord was trying to give me a choice to live forever or burn in hell in the bottomless pit. That is when I accepted the Lord in my life. (Narrative 23)

Some North Carolina respondents noted that their NDEs had elements that differed from their expectations of the afterlife. No narrative mentioned "judgment" preceding entry to heaven, a concept advocated by many Christian denominations. (Perhaps 80 percent of people in northeastern North Carolina are Baptist.) As in medieval Europe and Asia, where NDErs described forms of "purgatory" before the concept became canonized (McClenon, 1991, 1994), modern NDErs advocate theological innovation, portraying easy entrance to heaven. Nonjudgmental NDEs are functional for pluralistic societies, where people from different ethnic, social, and religious groups live in close proximity.

The higher incidence of negative emotions within this sample may be related to ethnicity and associated anxiety, unusual sleep patterns, and high blood pressure. Hypertension among African-Americans is about twice as prevalent as among whites. Panic disorder, anxiety disorder, and sleep paralysis, thought to be interrelated, are also far 
more prevalent among African-Americans and may be related to hypertension (Bell, Dixie-Bell, and Thompson, 1986; Bell, Shakoor, Thompson, Dew, Hughley, Mays, and Shorter-Gooden, 1984; Neal and Turner, 1991; Williams and Collins, 1995). Although random sample survey results indicate equivalent reporting of most forms of anomalous experience among two predominately white college samples and the predominately African-American ECSU sample, the ECSU rates of sleep paralysis were 13 to 18 percent higher (McClenon, 1994).

Carl Bell, Bambade Shakoor, Belinda Thompson, Donald Dew, Eugene Hughley, Raymond Mays, and Kumea Shorter-Gooden (1984, p. 506) argued that "a great number of black persons suffer from 'survival fatigue,' a situational predicament that may result in an over aroused adrenergic central neurobiologic system, leading to a variety of behaviors, attitudes, and psychophysiologic diseases." People under stress and suffering from hypertension may have greater tendency to experience sleep paralysis and to report negative emotions as a result of anomalous perceptions (McClenon, 2002b).

\section{Hypothesis 4: The Shamanic Nature of NDEs: Individual Transformation}

The ritual healing theory hypothesizes that NDEs are one of various forms of anomalous experience that provide bases for shamanism. It predicts that any large collection of NDEs should include stories portraying shamanic processes: people who experience frequent anomalous episodes gain absolute faith in spirits, souls, life after death, and magical abilities. They are regarded by others as "special" and tend to become shamans, psychics, or spiritual healers.

One case directly supports this hypothesis. While in the hospital, a 30-year-old woman perceived an NDE that included feelings of peace, an OBE, meeting others, seeing the light, coming back, telling others, effects on life, new views of death, and corroboration. She reported that when she was a child she was considered "special" because of the many apparitions she perceived. She described frequent conversations with a deceased uncle when she was 5 years old, before she realized he was dead. She told of apparitional visits by a deceased grandfather and a precognitive dream of a shooting in her neighborhood. She described a waking extrasensory perception that foretold a relative's death. She reported many precognitive dreams: a wake that corresponded exactly with later events, a miscarriage experienced by a woman at her work, a trip to Richmond for a medical appointment, and a bald stranger 
whom she later recognized as her brother's attorney, even though he wore a hairpiece, and who became an important person in their lives.

She described a series of precognitive dreams regarding winning numbers in the Maryland lottery. She won small amounts on three occasions and her cousin won a larger sum through playing a number she provided (McClenon, 2002a, p. 139). These experiences made her certain regarding spiritual forces, life after death, and her own magical abilities. She acquired a reputation in her community as a spiritual healer and advisor, someone whose prayers were often answered. As a result, people often asked her to pray for them. Her NDE contributed to her beliefs:

It's like this, [Jesus] touched my hand and it's like - now, no matter what happens, I really know He's there for me. It's made a difference for me - how I think - how I treat other people. ... I ask Him for guidance and I try to take the steps as He guides me. But I don't worry about anything because I don't need to. I know that I'm only going to be here for a little while and when I go, I know there is going to be complete peace. I'm not afraid of dying. (Narrative 1)

This respondent stressed that her NDE was merely one of many experiences creating "transformation." People who see apparitions of deceased relatives, have frequent dreams that come true, and perceive visions corresponding with reality perceive themselves as changed and tend to take up shamanic roles as a result.

A second example portrays how those with multiple otherworldly experiences gain certainty regarding life after death. A 53-year-old man described a non-crisis OBE that included six of Moody's core features and scored 7 on Greyson's NDE scale. His first experience alarmed him; after repeated experiences, he came to believe that he could control his perceptions:

Since this occurrence, I have had this same thing happen to me several times. From these experiences, I feel that it is possible that the dying process may have some human choice involved in it. I feel that it may allow you to ultimately control your final destiny. Even though we are overpowered by the stresses of everyday life, the light that I saw makes you think and see that Jesus has given us a final escape route from the truly unbearable aspects of life. (Narrative 22)

\section{Hypothesis 4: The Shamanic Nature of NDEs:} Individual Transformation

The idea of control is at the heart of shamanism. The shaman gains control of his or her cognitive processes and, as a result, is able to visit 
the spirit world and gain concessions from spiritual forces. As with NDEs, the other forms of anomalous experience can involve "corroboration" of compelling belief. Those who have frequent anomalous experiences accept the authenticity of magical claims. For example, an adult male described repeated OBEs. He knew his mother was sick and purposefully attempted to "visit" her spiritually:

You may not believe this, but I tell you every word of it is true. For
years I have had this ability to leave my body to go and visit someone
who may be in trouble or who is dying. When my mother was dying I
went to visit her, not in person but spiritually. ... I went in my room
and got down on my knees like I was praying. The next thing I knew I
was with my Mama. We talked and talked about all those good times
we used to have and she told me that she was going to be all right and
to go back to myself and not grieve because she was going to be in
heaven and would be watching down over me. When I came back
everybody was around me and they told me I must have passed out.
I looked at them and said, "No, I was with Mama." (Narrative 20)

This man's father stated that others had verified many of his son's previous anomalous experiences and that the episode his son described coincided with his wife's death within 15 minutes.

These cases illustrate a pattern found around the world. Humans have a natural propensity for shamanic experience. Certain people who experience frequent anomalous events develop powerful beliefs and acquire shamanic roles within their communities. This evidence supports the ritual healing theory.

\section{Hypothesis 5: The Social Impact of NDEs: Social Transformation}

The ritual healing theory argues that NDE stories shape folk beliefs regarding life after death. This process was documented by requiring interviewers to summarize their reactions to each informant's story and by asking coders to explain why they found certain stories to be particularly interesting.

Qualitative analysis of these results provides insights into processes by which some stories gain wide distribution, affecting folk beliefs. Interviewers provided a variety of opinions, from strong skepticism to absolute belief.

The few skeptical comments often included theological arguments. These cases fail to support the hypothesis that NDEs 
generate social transformation. For example, one student interviewer commented:

Though many people in a near death situation will say they have visited Heaven none have actually died. There is a difference between biological death and clinical death. Biological death is permanent; clinical death is a subnormal condition that can change. The lights people report are the operation room lights. Also hearing is the last sense a person loses when they are impaired or in a coma. They are hearing the voices of the medical people, not angels. It is pleasant to think that there is life after death, yet the vast majority of people who are religious or who tell these stories drink, divorce, commit adultery, etc., acts that are not permitted for those who will go to Heaven. (Narrative 11)

This text illustrates typical arguments disputing NDE authenticity. People tend to reject accounts that do not coincide with their previous beliefs.

More typically, interviewers stated that NDE accounts caused them to evaluate their beliefs from the vantage point of the experiencer. They indicated that the story caused them to ponder the meaning of individual experience in relation to belief, concepts central to shamanism:

This is something that you hear about but never think actually happens to a real person. It makes me think about the way I am living. (Narrative 26)

When people hear that someone has died and come back to life, they often label the person as crazy. But if you think about it, Jesus died and came back to life. If you believe that then why is it so hard to believe that another human could not do the same? (Narrative 5)

I had never given any thought to these types of things. I was very interested in what Mrs. M. had to say because it just seemed so unreal. While she was talking, I got goose bumps. I felt spooked thinking that it really happened. It made me think that when we die, our spirits or souls really leave the body, and not just die with our mortal beings. I had always believed in life after death because of religious reasons, but there's a difference in believing something and hearing that it has actually happened. (Narrative 6)

Although no interviewer described being "converted" as a result of talking to an NDEr, some expressed admiration for the powerful beliefs associated with the experience. People who have had many experiences often provide a model for others by exemplifying the value of belief.

Student coders were asked to list the three stories they found most interesting and to describe why they chose those particular stories. 
Four stories received three or more votes, three of which have been discussed previously. Ironically, among these four most-favored stories, only one was a crisis NDE. These stories were: (1) the woman who reported an extremely large number of anomalous perceptions, one of which was an NDE (Narrative 1); (2) the man who claimed to engage regularly in out-of-body travel and who visited his mother as she died (Narrative 20); (3) the woman, not involved in a crisis, who had a vision of hell and heaven (Narrative 23); and (4) a man who saw his deceased relatives immediately before he died (Narrative 3 ). This last experience was classified as a deathbed vision and not included in the quantitative analysis, since equivalent cases were not included in other researchers' NDE samples.

Students described why these particularly stories were interesting. Many mentioned that some people were able to control these episodes, using their abilities to gain benefits. This capacity is central to shamanism and these stories tend to cause audiences to accept fundamental shamanic doctrines. Some students stated that the helland-heaven vision represented their own religious beliefs and, as a result, they regarded this story to be particularly valid. Coders also selected the deathbed vision as interesting due to the empathy this story elicited, as it went into much detail describing the suffering of a dying man. Although the story was presented in a rambling, unorganized style, coders stated that they identified with the storyteller's grief, a process that led to feeling the storyteller's joy when his father glimpsed deceased relatives before dying.

Some students described emotional processes as part of their evaluations. For example, various students found a story told by a young woman to be particularly powerful. She reported an NDE while suffering childbirth complications, during which she chose life on earth rather than entrance to heaven so that she could raise her newborn child. Such stories provide healthy ways for people to think about the problems they face, such as the stress associated with childrearing.

The evaluation indicated (1) that people are interested in stories that portray shamanic perspectives, the idea that some people have the ability to experience and control spiritual realities; (2) that although people tend to be attracted to stories coinciding with their beliefs, some change their opinions as a result of hearing NDEs; and (3) that people like stories portraying emotional, therapeutic themes.

These findings allow insights into the processes by which folk beliefs evolve. NDE accounts are selected and shaped through retelling, 
resulting in accounts that serve people in a particular community. Certain stories gain particular importance, emphasizing valued themes.

\section{Conclusions}

Although conclusions are tentative due to the limited number of narratives, results coincide with predictions derived from the ritual healing theory. First, the narrative collection contains accounts with NDE core features, implying a biological basis. Second, comparing crisis to non-crisis accounts reveals almost no difference in incidence of these features. This suggests that NDEs are derived from a visionary process rather than the physiology of dying. Third, NDErs' culture and expectations contribute to NDE content, creating features that differ among cultures. Fourth, NDEs are one of various forms of anomalous experience that lead some people to take on shamanic roles. And fifth, reports of NDEs shape folk beliefs regarding life after death.

This study illustrates how the ritual healing theory can be tested empirically. Study weaknesses include small sample size, marginal coder reliability, comparison with findings from studies with different collection methods, and use of qualitative hypotheses. The small sample size in particular makes inferential tests of significance problematic, as relatively large differences in means are required to achieve statistical significance. As noted above, methodological differences in story collection, interviewing, transcription, and coding may have contributed to quantitative differences between the North Carolina sample and previously published studies. Study strengths include quantitative comparison and analysis, multiple coders, multiple scales, and methodology suitable for replication.

\section{References}

Becker, C. B. (1981). The centrality of near-death experience in Chinese Pure Land Buddhism. Anabiosis: Journal of Near-Death Studies, 1, 154-171.

Becker, C. B. (1984). The Pure Land revisited: Sino-Japanese meditations and near-death experiences of the next world. Anabiosis: Journal of Near-Death Studies, 4, 51-68.

Bell, C. C., Shakoor, B., Thompson, B., Dew, D., Hughley, E., Mays, R., and ShorterGooden, K. (1984). Prevalence of isolated sleep paralysis in black subjects. Journal of the National Medical Association, 76, 501-508.

Bell, C. C., Dixie-Bell, D. D., and Thompson, B. (1986). Further studies on the prevalence of isolated sleep paralysis in black subjects. Journal of the National Medical Association, 78, 649-59.

Blackmore, S. (1993). Dying to live: Near-death experiences. Buffalo, NY: Prometheus.

D'Onofrio, B. M., Eaves, L. J., Murrelle, L., Maes, H. H., and Spilka, B. (1999). 
Understanding biological and social influences on religious affiliation, attitudes, and behaviors: A behavior genetic perspective. Journal of Personality, 67, 953-984.

Eliade, M. (1974). Shamanism: Archaic techniques of ecstasy. Princeton, NJ: Princeton University Press.

Emmons, C. F., and Emmons, P. (2003). Guided by spirit: A journey into the mind of the medium, Lincoln, NE: iUniverse.

Fox, M. (2003). Religion, spirituality and the near-death experience. London, England: Routledge.

Green, J. T. (1996, Spring). Journeys into the light: Near-death experience as an ecstatic initiation. Shaman's Drum, pp. 49-54.

Green, J. T. (1998). Near-death experiences, shamanism, and the scientific method. Journal of Near-Death Studies, 16, 205-222.

Green, J. T. (2001). The near-death experience as a shamanic initiation: A case study. Journal of Near-Death Studies, 19, 209-225.

Greyson, B. (1983). The Near-Death Experience Scale: Construction, reliability, and validity. Journal of Nervous and Mental Disease, 171, 369-375.

Greyson, B. (1985). A typology of near-death experiences. American Journal of Psychiatry, 142, 967-969.

Greyson, B. (1990). Near-death encounters with and without near-death experiences: Comparative NDE scale profiles. Journal of Near-Death Studies, 8, 151-161.

Greyson, B. (2000). Near-death experiences. In Cardeña, E., Lynn, S. J., and Krippner, S. (eds.), Varieties of anomalous experience: Examining the scientific evidence (pp. 315-352). Washington, DC: American Psychological Association.

Haviland, W. A. (1997). Anthropology ( $8^{\text {th }}$ ed.). New York, NY: Harcourt Brace.

Irwin, H. J. (1985). Flight of mind: A psychological study of the out-of-body experience. Metuchen, NJ: Scarecrow Press.

Kellehear, A. (1996). Experiences near death: Between medicine and religion. New York, NY: Oxford University Press.

Kellehear, A. (2001). An Hawaiian near-death experience. Journal of Near-Death Studies, 20, 31-35.

Kumar, V. K., and Pekala, R. J. (2001). Relation of hypnosis-specific attitudes and behaviors to paranormal beliefs and experiences: A technical review. In Houran, J., and Lange, R. (eds.), Hauntings and poltergeists: Multidisciplinary perspectives (pp. 260-279). Jefferson, NC: McFarland.

Lange, R., Greyson, B., and Houran, J. (2004). A Rasch scaling validation of a "core" near-death experience. British Journal of Psychology, 95, 151-177.

Lynn, S. J., and Sivec, H. (1992). The hypnotizable subject as creative problem-solving agent. In Fromm, E., and Nash, M.R. (eds.), Contemporary Hypnosis Research (pp. 292-333). New York, NY: Guilford Press.

McClenon, J. (1991) Near-death folklore in medieval China and Japan: A comparative analysis. Asian Folklore Studies, 50, 319-42.

McClenon, J. (1994). Wondrous events: Foundations of religious belief. Philadelphia, PA: University of Pennsylvania Press.

McClenon, J. (1997). Shamanic healing, human evolution, and the origin of religion. Journal for the Scientific Study of Religion, 36, 345-54.

McClenon, J. (2000) Content analysis of an anomalous memorate collection: Testing hypotheses regarding universal features. Sociology of Religion, 61, 155-69.

McClenon, J. (2002a). Wondrous healing: Shamanism, human evolution, and the origin of religion. Dekalb, IL: Northern Illinois University Press.

McClenon, J. (2002b). Content analysis of an anomalous experience collection: Evaluating evolutionary perspectives. Journal of Parapsychology, 66, 291-315.

Moody, R. (1975). Life after life. Covington, GA: Mockingbird Books.

Moody, R., and Perry, P. (1988) The light beyond. New York, NY: Bantam. 
Morse, M., and Perry, P. (1992). Transformed by the light: The powerful effect of neardeath experiences on people's lives. New York, NY: Villard.

Murphy, T. (2001). Near-death experiences in Thailand. Journal of Near-Death Studies, $19,161-78$.

Neal, A. M., and Turner, S. M. (1991) Anxiety disorders research with AfricanAmericans: Current status. Psychological Bulletin, 109, 400-410.

Neihardt, J. G. (1988). Black Elk speaks: Being the life story of a holy man of the Oglala Sioux. Lincoln, NE : University of Nebraska Press. (Original work published in 1932.)

Ring, K. (1980). Life at death: A scientific investigation of the near-death experience. New York, NY: Coward, McCann and Geoghegan.

Ring, K. (1984). Heading toward omega: In search of the meaning of the near-death experience. New York, NY: William Morrow.

Ring, K. (1989). Near-death and UFO experiences as shamanic initiations: Some conceptual and evolutionary implications. ReVision, 11(3), 14-22.

Ring, K. (1990). Shamanic initiation, imaginal worlds, and light after death. In Doore, G. (Ed.), What survives? Contemporary explorations of life after death (pp. 204-215). Los Angeles, CA: Tarcher.

Ring, K. (1992). The omega project: Near-death experiences, UFO encounters, and mind at large. New York, NY: William Morrow.

Serdahely, W. J. (1991). Were some shamans near-death experiencers first? Journal of Near-Death Studies, 9, 255-257.

Sutherland, C. (1992). Reborn in the light: Life after near-death experiences. New York: Bantam.

Wade, J. (2003). In a sacred manner we died: Native American near-death experiences. Journal of Near-Death Studies, 22, 83-115.

Waller, N. G., Kojetin, B. A., Bouchard, T. J., Lykken, D. T., and Tellegen, A. (1990). Genetic and environmental influences on religious interests, attitudes, and values: $A$ study of twins reared apart and together. Psychological Science, 1, 138-142.

Williams, D. R., and Collins, C. (1995). US socioeconomic and racial differences in health: Patterns and explanations. Annual Review of Sociology, 21, 349-386.

Winkelman, M. (2000). Shamanism: The neural ecology of consciousness and healing. Westport, CT: Bergin and Garvey.

Zaleski, C. (1987). Otherworld journeys: Accounts of near-death experience in medieval and modern times. New York, NY: Oxford University Press. 